\title{
PORTO COMO TERRITÓRIO DE TRABALHO: manifestações de trabalho no Porto de Parintins
}

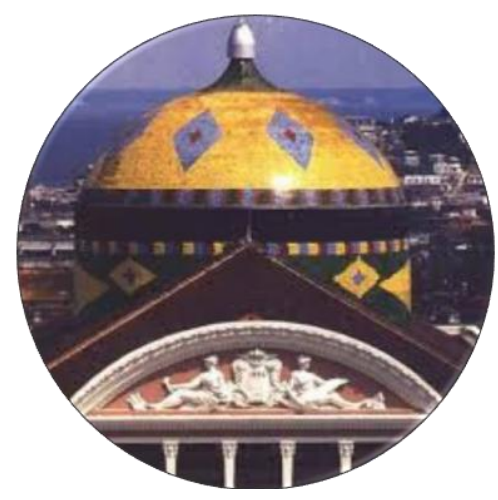

Adelson da Costa Fernando ${ }^{1}$

Laranna Prestes Catalão ${ }^{2}$

\begin{abstract}
Resumo
Este artigo propõe a compreensão do porto de Parintins como território de trabalho e a inteligibilidade das várias expressões de trabalho que se estabelceram nesse espaço. A cidade de Parintins, cidade amazônica à beira-rio, está situada à margem direita do Rio Amazonas; distante $420 \mathrm{~km}$ via fluvial de Manaus; é um território em que se vislumbram várias modalidades de expressão de trabalho, através das quais é possível a compreensão de um pedaço dessa complexidade que é a Amazônia. Além dos trabalhadores portuários avulsos, outros segmentos labutam diariamente no Porto: vendedores de artigos diversos e alimentação, taxistas, moto taxistas, tricicleiros, vendedores de passagens de barcos, navios e lanchas expressas e os trabalhadores avulsos não-portuários - amarradores de embarcação e carregadores e transportadores de bagagens.
\end{abstract}

Palavras-chave: Porto de Parintins. Território de Trabalho. Linguagem. Amazônia.

\begin{abstract}
This article proposes the understanding of the port of Parintins as work territory and the intelligibility of the various expressions of work that have established themselves in this space. The city of Parintins, an Amazonian city by the river, is situated on the right bank of the Amazon River; $420 \mathrm{~km}$ from Manaus; is a territory in which various forms of expression of work are seen, through which it is possible to understand a piece of this complexity that is the Amazon. In addition to the single port workers, other segments
\end{abstract}

1 Sociólogo, Mestre em Sociedade e Cultura na Amazônia e Professor Assistente do Instituto de Ciências Sociais, Educação e Zootecnia/ICSEZ (Email: coordenador.fbn@hotmail.com).

2 Mestranda no Programa de Pós-graduação em Serviço Social e Sustentabilidade na Amazônia (PPGSS)/UFAM (E-mail: larannaprestes@gmail.com). 
work daily in Porto: sellers of miscellaneous items and food, taxi drivers, motorcycle taxi drivers, trunks, boat ticket vendors, express boats and express boats and non-port workers - boat tie-downs and shippers and baggage transporters.

Keywords: Port of Parintins. Territory of Work. Language. Amazon.

\section{O porto como território de trabalho: algumas considerações}

Todos os territórios construídos pelos vários segmentos de trabalhadores, que recebem a materialidade dinâmica de seu trabalho, possuem regras sociais exercidas pela coletividade que define as expressões específicas de seus papéis no interior das relações sociais de sua categoria.

Nesse sentido, o território de trabalho pode ser pensado aqui como "um produto das ações coletivas, uma construção histórica do homem à medida que esse se organiza culturalmente”. Ao se reproduzirem num dado espaço, "cria-se e recria-se a identidade coletiva entre os indivíduos e o território onde desenvolvem suas atividades produtivas" (PEREIRA, 2009, p. 216). Assim, Almeida (2007) afirma que é o fator identitário e todos os outros fatores a ele subjacentes, que levam as pessoas a se agruparem sob uma mesma expressão coletiva, a declararem seu pertencimento a um povo ou a um grupo, a afirmarem uma territorialidade específica e a encaminharem organizadamente demandas ao Estado, exigindo reconhecimento às suas formas intrínsecas de acesso à terra. Almeida (2007) afirma que a noção "territorialidades específicas" pode ser considerada, portanto, como resultantes de diferentes processos sociais de territorialização e como delimitando dinamicamente terras de pertencimento coletivo que concorrem para um território.

A geografia crítica, encabeçada no Brasil pelo geógrafo Milton Santos, traz grandes contribuições com base numa elaboração teórica acerca do espaço e de como ela pode contribuir significativamente para o entendimento dos processos no território de trabalho nos portos em Parintins. 
Estudar a dinamicidade do território de trabalho, particularmente dos vários segmentos encontrados no porto de Parintins, se sustenta no pressuposto de que "o homem transforma o ambiente por meio da técnica (trabalho) e cria uma segunda natureza". Daí a importância de privilegiar em qualquer estudo acerca das condições de vida dos trabalhadores a noção de espaço articulado como um status de 'lugar', tendo em vista que “é onde se realiza a sua produção da vida, ao mesmo tempo, que se criam nele as condições para sua reprodução" (GONDIM, p. 59). Esse movimento constante de produção e reprodução da vida no espaço, entre fixos e fluxos (ações e objetos), cria uma dinâmica própria em cada lugar, decorrente da singularidade das condições de existência (socioeconômicas, políticas, institucionais, ecológicas, culturais, étnicas etc.) da população, dos segmentos e categorias sociais, dos trabalhadores. Isto significa dizer que o meio ambiente é a fonte de recursos que garante a sobrevivência das espécies e também o espaço onde elas se reproduzem (ODUM, 1988; FORATTINI, 1992).

É nesse sentido que para Santos (1996), o espaço não é um 'palco' onde fatos acontecem, tampouco uma caixa-preta onde informações são armazenadas. É, simultaneamente, conteúdo e contingente, sendo resultado das relações que o materializam: um processo constante e indissolúvel de interações entre sistemas de objetos e sistemas de ações. Então dá pra dizer que o espaço é um sistema de valores que se transforma permanentemente pela ação humana; assim, a natureza do espaço é resultado material acumulado das ações humanas pelo tempo, e, de outro lado, animado pelas ações atuais que hoje lhe atribuem um dinamismo e uma funcionalidade (SANTOS, 2002). Também podemos compreender que o espaço é anterior ao território (RAFFESTIN, 1993), e que ele é condicionado pela racionalidade de quem o usufrui.

O território é também um espaço, porém singularizado: sempre tem limites que podem ser político-administrativos ou de ação de um 
determinado grupo de atores sociais. Internamente é relativamente homogêneo, com uma identidade que vai depender da história de sua construção, e o mais importante: é portador de poder - nele se exercitam e se constroem os poderes de atuação tanto do Estado quanto das agências e de seus cidadãos (GONDIM, p. 238). Daí sua importância estratégica para as políticas sociais públicas na consolidação de ações para o enfrentamento de problemas e necessidades da população que o habita e o produz socialmente (CLAVAL, 1979 apud GONDIM, p. 238). Para Giddens (1989) apud Gondim, p. 239, esse poder criado pelas estruturas do Estado e da sociedade civil organizada se institui por meio das redes de relacionamento humano que se constituem no espaço.

Os aportes teóricos de Sack (1986), Raffestin (1993) e Cox (1991) apud MONKEN, 2008, p. 27, permitem-nos distinguir território e territorialidade e entender a constituição do território como um processo, no qual existem superposições de intenções de diferentes atores e conflitos. Um mesmo espaço pode conter diversas territorialidades que resultam em territórios com configurações, temporalidades e objetivos distintos. Essas territorialidades podem criar territórios temporários, permanentes, intermitentes, estáveis, instáveis, contínuos, descontínuos, com expressão em diferentes escalas (SOUZA, 1995). Desse modo, intenção, apropriação, poder, delimitação e identidade são alguns dos fundamentos sem os quais não se pode pensar o território (MONKEN et al., 2008, p. 29).

O conceito de território pressupõe a categoria espaço, que é o fundamento básico de uma comunidade ou de uma sociedade, onde se constroem as relações sociais e repousam os objetos naturais (as coisas da natureza) e materiais (elementos que resultam do trabalho). É preciso que vejamos o espaço como um sistema de objetos e, ao mesmo tempo, como um sistema de ações. Isso significa dizer que o espaço é dinâmico, pois pressupõe o empreendimento de ações humanas na sua configuração (SANTOS, 2002; BRITO, 2010, p. 76). O espaço se transforma em 
território à medida que o revestimos de significados, sejam eles simbólicos ou materiais, afetivos ou míticos (TUAN, 1983). Ou seja, o território é uma representação social e coletiva, uma ordenação primeira do espaço. Nesse contexto, a afetividade e o pertencimento ao lugar podem ser considerados formas de valor agregado, assim como o conhecimento e a práxis das atividades produtivas realizadas no território. Por isso se pressupõe que o território é produto das ações coletivas organizadas; à medida que é pensado e organizado, cultural e socialmente pelo trabalho coletivo, dá visibilidade aos grupos sociais que passam a operacionalizá-lo mediante regras de uso.

Ao utilizar o conceito de território de trabalho devemos estar atentos para as orientações sugeridas por Santos e Silveira (2001, p. 12): “o território, em si mesmo, não constitui uma categoria de análise ao considerarmos o espaço geográfico como tema das ciências sociais, isto é, como questão histórica. A categoria de análise é o território utilizado”. Ou seja, não faz sentido pensar no território como mera delimitação de uma área; é preciso reconhecer processos e territorialidades que muitas vezes transgridem limites impostos por atores determinados (GONDIM, p. 252). É preciso conhecer o território, sua população e os processos que aí se desenvolvem (o território usado), bem como reconhecer as múltiplas e diversas territorialidades existentes na denominada 'arena territorial' (COX, 1991 apud GONDIM, p. 252). Daí, entender as estruturas portuárias como territórios de trabalho significa descobrir a (re) significação dos espaços pelas categorias sociais porque esse território carrega, de forma indissociável, uma dimensão simbólica ou cultural em sentido estrito, e uma dimensão material, de natureza predominantemente econômico e política (MONKEN et al., 2008, p. 27).

Assim, a noção de território é dinâmica quando pensamos no contexto social dos trabalhadores no porto de Parintins; principalmente quando consideramos a realidade social como constituída por uma relação 
intrínseca entre a dimensão espacial, ecológica, política, econômica e simbólica. A combinação desses fatores é condição sine qua non que fundamenta o conceito de território. Este conceito não pode ser pensado como uma realidade estática. Por ser um conceito dinâmico, ele deve ser contextualizado, pois expressa a dimensão histórica dos grupos sociais envolvidos. A orientação de se pensar os elementos ecológicos, políticos, sociais, econômicos e históricos intrinsecamente relacionados ao conceito de território provoca nosso olhar ao se observar manifestações singulares e de diferentes fenômenos ou situações que marcam o cotidiano dos trabalhadores que labutam no porto da cidade de Parintins, no Amazonas.

\section{A cidade de Parintins e o significado do Porto na Amazônia}

A cidade de Parintins, cidade amazônica à beira-rio, está situada à margem direita do Rio Amazonas. É uma das ilhas do Arquipélago das Tupinambaranas, distante $420 \mathrm{~km}$ via fluvial de Manaus, capital do Estado do Amazonas. A cidade de Parintins é um território em que se vislumbram várias modalidades de expressão de trabalho, através das quais é possível a compreensão de um pedaço dessa complexidade que é a Amazônia, no dizer de Oliveira (2007, p. 171): "Não porque essas cidades sejam importantes do ponto de vista econômico e político, mas porque são lugares em que pulsam modos de vida que diferem significativamente do padrão caracterizado como urbano em outras regiões do Brasil”.

A vida nas e das cidades amazônicas está ligada ao rio e à floresta (OLIVEIRA, 2007, p. 171). A obra O rio comanda a vida, do historiador Leandro Tocantins (2000), expressa com clareza essa profunda relação, sobretudo do rio Amazonas, com a vida regional. Governando o labiríntico sistema orográfico, como aranha no centro de uma teia, o Amazonas é um fator de incansáveis metamorfoses. Prestigiador da realidade, ele transfigura, hipnotiza, solapa, restaura, faz aparecer e reaparecer ilhas, 
esconde embarcações encantadas na manga de sua casaca de ondas, devora cidades, alimenta populações, guarda em suas profundezas ricas encantarias habitadas pelos botos, iaras, boiúna, cobras-norato (FRAXE, 2004, p. 331).

É pelo rio que a vida amazônica adquire efervescência, fluxo e dinamicidade. "Nos rios abrem-se um cenário de terras e de florestas. A Amazônia nasce, desenvolve-se, perdura, segundo o evangelho escrito pelo rio" (TOCANTINS, 2000, p. 266). Os rios na Amazônia constituem uma realidade labiríntica e assumem uma importância fisiográfica e humana excepcionais. O rio é o fator dominante nessa estrutura fisiográfica e humana, conferindo um ethos e um ritmo à vida regional. Dele dependem a vida e a morte, a fertilidade e a carência, a formação e a destruição de terras, a inundação e a seca, a circulação humana e de bens simbólicos, a política e a economia, o comércio e a sociabilidade. O rio está em tudo (FRAXE, 2004, p. 330).

As cidades amazônicas estão integradas entre si e se comunicam com as comunidades através das canoas, barcos, motores, lanchas, navios, entre outras embarcações. São nesses transportes principalmente que a vida ribeirinha é transportada e que a vida cabocla é dinamizada. Essas embarcações não conduzem simplesmente pessoas e mercadorias; nelas ocorrem uma multiplicidade de relações, processos, trabalho, conflitos, encontros, desencontros, diferenças, aproximações: é “o rio enchendo a vida do homem de motivações psicológicas, o rio imprimindo à sociedade rumos e tendências, criando tipos característicos na vida regional" (TOCANTIS, 2000, p. 277), porque o rio é um "poderoso gerador de fenômenos sociais" (TOCANTINS, 2000, p. 276).

São muitos os processos, ações e relações que se verticalizam nos trajetos que se desenham entre as comunidades e cidades, protagonizados pelos trabalhadores no exercício de seus papéis; que no cenário do rio e da floresta são quase invisíveis na perspectiva de suas tramas, de seus dramas, das suas percepções, da busca da sobrevivência e das suas inquietações. 
Os barcos navegam na "epiderme dos rios" (FRAXE, 2004, p. 332); sobre ele viaja o caboclo, observando, estudando a natureza, conhecendo os sinais da chuva, da tempestade, do vento, da calmaria, dos dias e das noites (FRAXE, 2004, pp. 331-332). O rio é uma estrada líquida, cortado por atores que lhe imprime relações e processos dinâmicos, que precisam ser desvelados. É deste modo que para Tocantins, “o homem e o rio são os dois mais ativos agentes da geografia humana da Amazônia” (2000, p. 277).

Interligado a toda essa paisagem encontra-se o porto que funciona como o coração da cidade, tendo em vista que é por ele que se permite a dinâmica dos lugares em seus aspectos econômicos, sociais e culturais. O porto é, por excelência, o ambiente pelo qual são importados e escoados produtos e insumos e onde acontece o embarque e desembarque de pessoas (PRESTES, 2011, p 45). Deste modo, este ambiente é considerado um território, no qual se constrói um sistema de objetos espaciais/geográficos articulados por um sistema de ações históricas e culturais, a partir da dinâmica entre rio e cidade.

As embarcações emolduram a orla fluvial que se transfigura em um território de relações humanas efervescentes e de toda uma movimentação da metrópole em direção ao rio e o movimento do rio rumo à metrópole, de modo que é na confluência dessas circulações e processos que está posto o núcleo de sua dinâmica (PRESTES, 20011, P. 68). Esse território portuário é lugar de descobrimentos, de eventos significativos, de embates, encontros e despedidas. Os rios têm a sua importância registrada na história biográfica dessas cidades beira-rios, mesmo com a existência de vias rodoviárias, aeroportos e outras formas de comunicação e transporte.

O porto de uma cidade, mesmo sendo o lugar do transitório (OLIVEIRA, 2007, p. 172), liga a cidade com seus outros caminhos e estradas; liga o rio com a terra; as pessoas com a dinâmica do lugar; a economia com a cultura; os processos de produção/reprodução com a sociabilidade. No porto flui uma dinâmica surpreendente da cidade que é 
apreendida e expressa com muita propriedade nos seguintes termos: $\mathrm{O}$ porto é por onde se chega e se vai; ele contém a possibilidade do entendimento da cidade, pois a vida começa no porto, menos pelo movimento, mais pelo fato de ele encerrar quase tudo que a cidade possui e que nela falta. O porto é o intermédio entre o rio, a floresta e a cidade, lugar privilegiado dos enigmas amazônicos, transfigurados em enigmas do mundo, a nos interrogar sobre o nosso passado, presente e futuro. $\mathrm{O}$ rio, a floresta e a cidade têm no porto a fronteira entre a realidade e a ficção, possibilitando-nos leituras múltiplas de espaços-tempos diversos (OLIVEIRA, 2007, p. 172).

O Porto de Parintins é um território de trabalho. No processo de organização da produção capitalista, o território transmuta-se de condição a meio de produção, por intermédio da intromissão do capitalista na relação entre o trabalhador e os instrumentos de trabalho (PENHA, 2005, p. 10 apud PRESTES, 2011, p. 68). O porto de Parintins é a origem da trajetória dos trabalhadores das embarcações fluviais com destino ao porto de Manaus. Nesses portos o movimento é intenso durante o turno matutino, horário freqüente de embarque e desembarque com trânsito de embarcações de cargas e passageiros. Especificamente no porto de Parintins, os transatlânticos aportam na cidade com turistas do mundo todo que visitam a cidade para conhecer o Festival folclórico da cidade e os bois Garantido e Caprichoso ou para participar da festa da padroeira do lugar, Nossa Senhora do Carmo (PRESTES, 2011, p. 71).

Olhar a cidade de Parintins, a partir do porto da cidade, nos sugere privilegiar dentre as várias formas de trabalho nesse território portuário, a compreensão do ambiente de trabalho do aquaviário, seus lugares, suas particularidades, seus espaços de sociabilidade, tradições, suas lutas pela sobrevivência em condições de precariedade, e seus modos de viver na "cidade do folclore", além de entender as suas formas de resistência e protagonismo político (PINHEIRO, 2003, p. 47). Numa leitura fundante 
das ideias de Neves, a partir delas é possível dizer que este segmento dos aquaviários, pela relação que estabelecem com o rio, com o porto, com a realidade das embarcações fluviais, são portadores de saberes, técnicas, estratégias e alternativas muito específicas pela convivência na realidade de seu território de trabalho, como também são alcançados por efeitos insalubres e insustentáveis das condições precárias de trabalho (NEVES, 2005).

No mundo do trabalho dos portos da Amazônia, os processos de trabalho sempre se deram de modo precarizados, tanto nas relações trabalhistas quanto no meio ambiente, principalmente nas instalações portuárias: trapiches de madeira, e balsas sem proteção que funcionavam como ancoradouro, modelo construído nos Portos de Manaus e reproduzido nas demais cidades amazônicas (SANTANA \& SCHERER, 2009, p. 225). Paixão e Fleury esclarecem que o porto é território de ampliação do grau de complexidade produzido e estruturado pela cidade (2008 apud PRESTES, 2011, p. 68).

A Organização Internacional do Trabalho (OIT) foi responsável por importantes publicações acerca da proteção social dos trabalhadores portuários. Dentre estas se destacam a Convenção 137 e a Recomendação 145 que foram legitimadas no Brasil através do Decreto no 1.574, de 31 de julho de 1995 e a Norma Regulamentadora (NR) no 29, respectivamente. A Convenção 137 foi adotada no Brasil em 1985 e tem por objetivo proteger o trabalhador portuário frente ao processo de automação, flexibilização e redução da mão-de-obra, decorrente da crise dos anos 1970. Já a Recomendação 145 apresenta a mesma preocupação com a modernização e as alterações no mundo do trabalho portuário a partir dos anos de 1970 e enfatiza a necessidade do emprego permanente ou regular aos trabalhadores portuários e a garantia do mínimo de seguros sociais possíveis na relação de trabalho (PAIXÃO; FLEURY, 2008). 
Nos portos brasileiros, as relações de trabalho estão sob a regência do Órgão Gestor de Mão-de-obra (OGMO), bem como dispõe a Lei $n^{\circ}$ 8.630/1993. É um órgão público e sem fins lucrativos, responsável pela centralização e administração da força de trabalho nos portos organizados, bem como apresenta o Capítulo IV desta Lei. Nesta esteira, o trabalho portuário pode ser realizado de duas formas: com vínculo empregatício a prazo indeterminado (contratação pela CLT) ou por trabalhadores avulsos portuários (BRASIL, 1993). No Porto de Parintins não existe o OGMO, mas sindicatos e associações que ditam o trabalho destes profissionais cada um exerce sua função e operam segundo a multifuncionalidade sob a vigência da "disciplina da fome” (DEJOURS, 1992). A fragilidade institucional destas organizações, trazidas pela crise do sindicalismo resultante da reestruturação produtiva, respondem à multifuncionalidade do trabalho e geram conflitos entre os segmentos do trabalho.

\section{A lei de modernização dos Portos de 1993 e o porto de Parintins}

A cidade de Parintins recebe o nome de "Parintins" em homenagem aos índios parintintins que nela habitaram em meados do século XVII. Sua história permeia as conquistas européias e espanholas nos rios amazônicos e as missões jesuíticas que chegaram a esta ilha em 1669, sob liderança do Pe. Felipe Bettendorff. Devido constantes doenças e perseguições no período pombalino, a cidade foi despovoada, mas reabitada em 1796 e denominada de "Tupinambarana" pelo capitão de milícias José Pedro Cordovil, sertanista português que deveria estabelecer a agricultura, mas optou pelo comércio de produtos naturais, utilizando violentamente os braços nativos (SAUNIER, 2003).

A agricultura passa a ser atividade principal neste povoado com a chegada de Frei José das Chagas, quando a ilha foi entregue a este missionário pelo Conde dos Arcos do Grão-Pará e que passou a ser 
chamada de "Vila Bela da Rainha", em 1798 (CERQUA, 1980). "Em pouco tempo a vila cresceu e se desenvolveu a agricultura, e como foi lembrado, foi introduzida a pecuária” (idem, p. 48).

Toda esta atividade econômica de produção de cacau, tabaco, mandioca, café e guaraná, além da pecuária, iniciada por Cordovil e Frei José, era escoada por uma rampa que também dava acesso a pessoas que desembarcavam no vilarejo; neste mesmo espaço, na orla fluvial, é onde funciona hoje o porto da cidade.

Bittencourt (2001), em sua obra "Memórias do município de Parintins: estudos históricos sobre sua origem e desenvolvimento moral e material", relata a árdua luta pela construção de um porto local, haja vista que a produção comercial era intensa desde 1876. O autor (idem, p. 60) afirma que:

No Relatório de 25 de Março de 1876, disse o Presidente da Câmara Legislativa à Assembléa Legislativa: 'Villa Bella, que é um ponto importante pela frequencia dos vapores, por sua população laboriosa, também não possúe uma matriz decente". [...] A outra necessidade, a que se referiu o Presidente, era a da construção da rampa, no porto”.

A dinâmica portuária que começa a se estabelecer com o intenso movimento de embarque e desembarque de passageiros, bagagens e cargas incentivou a construçao de uma rampa no espaço do porto, em 1876, para melhorar o tráfego de pessoas e mercadorias. Contudo, de acordo com Bittencourt (idem, p. 200):

[...] como era natural, devido ao grande tráfego sobre ella, a rampa ia precisando de concertos, que não eram realizados. Os dirigentes do Município não prestavam attenção aos reparos, resultando d'ahi o desapparecimento lento desse importante melhoramento. 
Paixão e Fleury (2008) elucidam que o porto é território de ampliação do grau de complexidade produzido e estruturado pela cidade. Tomando como referência a Mesopotâmia, localizada nas margens do rio Tigre e Eufrates, remonta a importância do porto fluvial, palco para o comércio e instalação de estrangeiros que não podiam ultrapassar os muros da cidade. Os autores consideram, ainda, o porto marítimo para a Grécia Antiga, uma vez que com a baixa fertilidade do solo e a pouca disponibilidade de terra para pecuária, os gregos dependiam do comércio que entravam pelo porto.

Segundo Jean Hatzfeld (1988, p. 145 apud PAIXÃO; FLEURY, 2008, p. 19):

As cidades dotadas com um bom porto podem desenvolver-se muito sem o risco da fome e, por outro lado, produzir em abundância, confiantes em poderem encontrar mercados externos, numa época em que a oferta é quase sempre inferior à procura [...] A história econômica da Grécia será doravante a dos seus grandes portos: Atenas, Siracusa, Rodes, Delos, Alexandria e Bizâncio.

Somente após a elevação da Vila à categoria de Província de Parintins, em 1880, esta mesma casa legislativa solicitou e aprovou a construção de um trapiche, mas sua execução só ocorreu em meados de 1930, pela administração local (BITTENCOURT, 2001). Funcionando com um trapiche de madeira, o porto de Parintins continuou sob administração local e sua manutenção se dava através de arrecadação de tarifas portuárias, também motivadas pela exportação de juta produzida pelos japoneses na cidade. Segundo a Capitania dos Portos, sua jurisdição tinha extensão desde a "Boca do Ramos à Boca do Limão", ou seja, toda a beira-rio da cidade.

Em meados de 1970, sua administração foi ao Estado "com a criação da Empresa de Portos do Brasil S/A - PORTOBRAS, uma "holding" que representava o interesse do governo em centralizar 
atividades portuárias [...] consolidando o Sistema Portuário Nacional" (KAPPEL, 2001), na esteira do que ocorreu a nível nacional. Esta adequação rendeu ao porto de Parintins e seus trabalhadores melhores condições de trabalho e armazenagem dos produtos e insumos que partiam e chegavam à cidade. Contudo, devido à crise institucional da Portobrás, deu-se sua extinção em 1990.

Envoltos pelo movimento de modernização e redemocratização do país, a problemática portuária e a indefinição de sua gerência é pauta no Congresso Nacional, motivada por seus vários atores como usuários, trabalhadores portuários e setores governamentais e privados. Desta construção, resulta a Lei de Modernização dos Portos, a Lei n ${ }^{\circ}$ 8.630, de 25 de fevereiro de 1993.

Para Paixão e Fleury (2008, p. 26):

Estava inaugurada, assim, uma nova era, um novo estágio, na administração da mão-de-obra portuária em todo o Brasil. Nesse contexto, a Lei 8.630/1993 não representa apenas uma modificação legislativa. É mais do que isso. Ela contempla um modelo preexistente, invertendo, em alguns aspectos, alguns dos vetores consagrados no marco legislativo anterior.

Segundo a Lei de Modernização dos Portos, o Porto é denominado como Porto Organizado (BRASIL, 1993):

[...] o porto construído e aparelhado para atender às necessidades da navegação e da movimentação e armazenagem de mercadorias, concedido ou explorado pela União, cujo tráfego e operações portuárias estejam sob a circunscrição de uma autoridade portuária. Os portos não enquadrados nessa situação são ditos "não organizados", não sendo as suas atividades reguladas pelo presente ordenamento. Os portos "não organizados" são geralmente pequenos e pouco movimentados, sem administração, resumindo-se, na maioria das vezes, a um pequeno cais para recebimento de mercadorias. 
O porto organizado é de responsabilidade da União, bem como preconiza a Lei $n^{\circ} 10.233$, de 5 de junho de 2001, que institui a Agência Nacional de Transportes Aquaviários (ANTAQ) e o Departamento Nacional de Infra-Estrutura de Transportes (DNIT). Estes órgãos fazem a gestão e estabelecem a reestruturação portuária, além de regular e dispor quanto aos portos organizados a fim de concretizar o disposto na Lei $\mathrm{n}^{\circ}$ $8.630 / 1993$.

Segundo a Lei de Modernização dos Portos, a Autoridade Portuária é responsável pela administração do porto organizado, competência da Sociedade de Navegação, Portos e Hidrovias do Estado do Amazonas (SNPH), instituída pelo Decreto $\mathrm{n}^{\circ} 23.904$, de 07 de novembro de 2003. A SNPH é uma empresa pública vinculada à Secretaria de Estado de Infra-estrutura, de sede e foro em Manaus/AM e jurisdição em todo o Estado e tem por finalidade o desenvolvimento da rede hidroviária interior, infra-estrutura portuária e navegação no Estado e exercício de Autoridade Portuária, executando tais atividades sob o princípio da descentralização. Assim, o Porto de Parintins é administrado por uma seção regional na qual seu supervisor local e os trabalhadores estão subordinados a esta seção sob regime celetista através de concurso ocorrido no ano de 2006.

Seguindo o programa de modernização, o Porto de Parintins foi totalmente reformado, em 2006, por meio do DNIT e supervisão da obra pelo Departamento de Engenharia do Exército Brasileiro. A nova estrutura física possui espaço de armazém, sala embarque e de desembarque, Serviço Social, Supervisão, Administração, sanitários/vestiários para funcionários e para públicos, área para restaurantes, lanchonetes, bancas de revista, artesanatos, agências bancárias, e postos da SEFAZ, do Juizado de Menores, da Capitania dos Portos, da Vigilância Sanitária e da Fiscalização do Ministério da Agricultura. Contudo, apenas os espaços destinados à administração portuária e trânsito de passageiros e armazéns de mercadorias funcionam regularmente no local, pois segundo o supervisor 
local, os demais órgãos ainda não direcionaram recursos humanos e equipamentos para seu devido funcionamento no porto.

A antiga balsa de dois pisos com a ponte fixa foi substituída por uma balsa com capacidade média de 2.250 toneladas e por uma ponte formada por uma parte móvel e outra fixa, para adaptar a dinâmica portuária aos ciclos das águas (enchente e vazante).

Em 2006 e 2009, a enchente ocasionada pela cheia do Rio Amazonas gerou diversas avarias ao prédio e, em meio à vazante de 2009, a ponte fixa que interliga a balsa e o prédio, alcança um ângulo de aproximadamente 70 graus, dificultando o trânsito neste espaço. Este ciclo das águas no Amazonas também são fatores preponderantes na organização do trabalho e de análise do território de trabalho. Portanto, Tocantins (2000, p. 276-277) explicita que:

Quando nas cheias a navegação alcança os sítios mais longínquos, certas vezes as alegrias do feliz acontecimento são toldadas pelas inundações funestas, arrasando culturas agrícolas, tragando barrancos, removendo a pobreza franciscana das barracas, levando o desespero aos lares, e constituindo uma séria ameaça à economia. Nos seis meses de seca o verão derrama sobre o vale o fulgor do sol em céu azul, descoberto, e o drama nos altos rios é a falta d'água no álveo empobrecido, a água contra a qual se blasfemara no desespero das alagações.

Por ocasião destes ciclos das águas, o Porto foi novamente reformado pelo DNIT sob supervisão do Exército Brasileiro. Em entrevista, o supervisor local da SNPH em Parintins, relatou que a obra ocorreu entre os meses de abril de 2010 a maio de 2011. Inicialmente, a área civil - prédio e estacionamento - compreendeu a elevação do piso da área civil em quase um metro para evitar as enchentes. A parte naval recebeu uma balsa com estrutura para atracação de embarcações de grande 
porte como navio de turismo e uma ponte maior para interligar balsa e área civil.

Em setembro de 2010, as adequações na parte naval obrigaram a interdição de trânsito no porto, sendo a movimentação portuária transferida para o "Porto do Dodó", como é conhecido o porto privado da Empresa Santa Rosa Serviços, localizado a beira-rio da cidade.

O porto improvisado abrange uma área de atracação para as embarcações de grande porte, mas devido sua localização, distante do centro da cidade, a dinâmica portuária foi dividida entre o "Porto do Dodó" e a orla próxima ao Porto de Parintins. Este local apresenta grandes riscos à saúde dos trabalhadores portuários que deram preferência ao trabalho neste local devido maior movimentação de mercadorias e passageiros quanto aos transeuntes que permitem esta dinâmica. $\mathrm{Na}$ entrada do porto, a pista de acesso à rampa é de concreto, contudo, no espaço à beira-rio destinado às embarcações, é uma rampa de barro batido que apresenta poeira agitada por caminhões e demais transportes motorizados em dias de sol e lama, nos dias chuva. Não há nenhum espaço para fuga das intempéries e por conta disso, ocorre uma confusão generalizada na dinâmica portuária.

\section{Considerações finais: as configurações de trabalho no Porto de Parintins}

É pelo e no porto de uma cidade que ocorrem uma diversidade de relações de trocas mercantis, onde se situam diferentes segmentos econômicos, os quais estão envolvidos com a venda da pesca, da madeira, dos animais silvestres, e dos produtos hortifrutigranjeiros, das frutas regionais, que chegam cotidianamente à beira rio. O porto é um lugar que comporta expressões complexas de modos de trabalhos múltiplos e diferentes, que vão do trabalho formal ao informal, diferentes modalidades 
de ganhos, de acesso aos serviços de consumo coletivo e de condições de vida.

Desse modo, o porto constitui-se um multifacetado território de trabalho (Haesbert, 2004), no qual se expressa a importância da diversidade de seus trabalhos na construção social da cidade. Nesses territórios de trabalho há um intricado diverso de tipos de trabalho: comerciantes, donos dos barcos regionais, vendedores ambulantes, os carregadores de bagagens e os trabalhadores das embarcações. Esse território de trabalho configurouse por múltiplas práticas e vivências humanas, com intensas redes de trocas econômicas, sociais, culturais e simbólicas que foram se reproduzindo no tempo e se espalharam no espaço urbano / fluvial parintinense.

A política de modernização do país, iniciada nos anos 90 no Governo Collor, que afetou também o setor portuário, faz parte do projeto neoliberal que trouxe a reestruturação produtiva do capital em resposta à crise que afetou a economia mundial nos anos de 1970. Sua principal característica é a imposição de um novo padrão de acumulação capitalista, fomentado pelas inovações tecnológicas e organizacionais, com base no "toyotismo", modelo japonês que atingiu principalmente a classe trabalhadora.

O Programa de Modernização, instituído pelo governo Collor, "procurava, além da abertura comercial, incentivar e obrigar o capital privado nacional a 'reestruturar-se e fortalecer-se', com o apoio de créditos oficiais, 'utilizados seletivamente e dirigidos exclusivamente para os investimentos necessários à reestruturação da indústria brasileira e à expansão do comércio exterior” (GOUVÊA, 1991 apud ALVES, 2010, p. 187).

Tal modernização atinge a relação capital $x$ trabalho principalmente na transferência da organização do trabalho e de registro dos sindicatos dos trabalhadores para os Órgãos Gestores de Mão-de-Obra (OGMO) e/ou contratos e normas pactuadas em convenções dos 
trabalhadores, corroborando com o que Alves (idem) apresenta como "o novo (e precário) mundo do trabalho", tendo como implicação desta ofensiva do capital, o trabalho precário e a crise do sindicalismo.

Nesta pesquisa, realizada no Porto de Parintins, constatou-se que os agentes portuários e integrantes do setor administrativo são concursados e os trabalhadores avulsos são regidos pela contratação eventual com os operadores portuários, donos de embarcações ou transeuntes.

A categoria "trabalhador portuário avulso" compreende as atividades de capatazia, estiva, conferência de carga, concerto de carga, vigilância de embarcações e bloco que devem estar capacitados e cadastrados ou registrados no OGMO. A diferença entre cadastrados e registrados é feita por Paixão e Fleury (2008, p. 31) nos seguintes termos: "o cadastro, no regime atual, complementa as equipes de trabalho na falta do registrado, ou seja, quando os registrados são aptos ao trabalho não são suficientes para o preenchimento das equipes".

Assim, o trabalho portuário deve primar pela negociação entre trabalhadores, mesmo que sejam avulsos, e seus contratantes afim de estabelecer condições mais adequadas ao trabalho, sendo que tais negociações são livres para atingir o limite do interesse público visando à melhoria dos serviços executados; deve vedar o trabalho aos profissionais que não forem portuários para que seja assegurada a qualificação profissional e os rendimentos auferidos dos que possuem qualificação; deve, ainda, garantir a equidade entre os trabalhadores; a execução de atividades que requeiram a mesma qualificação, independente da categoria a que pertencem; e, por fim, primar pela modernização tendo como marco a ruptura com o intervencionismo estatal. Todas estas características só enveredam a um caminho: privatização do espaço público, onde os transeuntes tornam-se clientes e os trabalhadores, mercadorias para o capital. 
Além dos trabalhadores portuários avulsos, outros segmentos labutam diariamente no Porto de Parintins: vendedores de artigos diversos e alimentação, taxistas, moto taxistas, tricicleiros, vendedores de passagens de barcos, navios e lanchas expressas e os trabalhadores avulsos nãoportuários - amarradores de embarcação e carregadores e transportadores de bagagens.

No Porto de Parintins não existe o OGMO, mas sindicatos e associações que ditam o trabalho destes profissionais - cada um exerce sua função e operam segundo a multifuncionalidade sob a vigência da “disciplina da fome" (DEJOURS, 1992). A fragilidade institucional destas organizações, trazidas pela crise do sindicalismo, resultante da reestruturação produtiva, respondem à multifuncionalidade do trabalho e geram conflitos entre os segmentos do trabalho.

São homens, mais do que máquinas, que possibilitam a dinâmica portuária nas cidades a beira-rio da Amazônia. É o trabalho dos homens da margem, os trabalhadores das águas, os trabalhadores da força física, que possibilitam a dinâmica portuária e é sobre esta ótica que esta pesquisa considera a importância dessas categorias sociais no Porto de Parintins, os quais foram negados, usurpados e esquecidos pelo processo de modernização.

\section{Referências}

ALMEIDA, A. W. B. Terras de quilombo, terras indigenas, "babaçuais livres", castanhais do povo, faxinais e fundo de pastos: terras tradicionalmente ocupadas. Manaus: PPGSCA, 2007.

ALVES, Giovanni. O novo (e precário) mundo do trabalho: reestruturação produtiva e crise do sindicalismo. São Paulo: Boitempo; FAPESP, 2010. (Coleção Mundo do Trabalho) 
BATICH, M. Previdência do trabalhador: uma trajetória inesperada. São Paulo: Perspectiva, 2004.

BENCHIMOL, Samuel. Navegação e Transporte na Amazônia. Manaus: Edição reprográfica, 1995.

BENCHIMOL, Samuel. Amarônia: formação social e cultural. 3 ed. Manaus: VALER, 2009.

BITTENCOURT, Antonio C. R. Memória do Município de Parintins: estudos históricos sobre sua origem e desenvolvimento moral e material. Manaus: Edições Governo do Estado, 2001.

BRASIL. Lei n 4.637, de 20 de maio de 1965. Dispõe sobre o exercício da profissão de carregador e transportador de bagagens em portos do País e dá outras providências.

Disponível em:

http://legislacao.planalto.gov.br/legisla/legislacao.nsf/8b6939f8b38f377a0 3256ca2000686171/7b01a0203e298baa032569fa0072954b?OpenDocument . Acesso em: 27 set 2009.

BRASIL. Lei no 8.630, de 25 de fevereiro de 1993. Dispõe sobre o regime jurídico da exploração dos portos organiz̧ados e das instalações portuárias e dá outras providências. (Lei dos Portos). Disponível em: http://www.planalto.gov.br/ccivil_03/LEIS/18630.htm. Acesso em: 10 set 2009.

BRASIL. Ministério do Trabalho e do Emprego. Secretaria de Inspeção do Trabalho. Manual do Trabalho Portuário e Ementário. Brasília: MTE, 2001a.

CARVALHO, Francisco Edivar. Trabalho portuário avulso antes e depois da lei de modernização dos portos. São Paulo: LTr, 2005.

CARVALHO, Francisco Edivar. Trabalho Marítimo à lur do Direito do Trabalho. Jus Navigandi, Teresina, ano 15, n. 2587, 1 ago. 2010. Disponível em: <http://jus.com.br/revista/texto/17091>. Acesso em 13 de março de 2013.

CERQUA, Dom Arcangelo. Clarões de fé no Médio Amazonas: a Prelazia de Parintins no seu jubileu de prata. Manaus: Imprensa Oficial do Estado do Amazonas, 1980.

DEJOURS, C. A loucura do trabalho: estudo de psicopatologia do trabalho. 5 ed. São Paulo: Cortez, 1992.

FRAXE, Therezinha de J. P. Cultura Cabocla-ribeirinha: mitos, lendas e transculturalidade. 2 ed. São Paulo: ANNABLUME, 2004. 
FONSECA, Osorio J. M. Pensando a Amazônia. Manaus: VALER, 2011.

FORATTINI, O. P. Ecologia, epistemologia e sociedade. São Paulo: EDUSP, 1992.

GONDIM, G. M. M. Espaço e Saúde: uma (inter) ação provável nos processos de adoecimento e morte em população. In: BARCELLOS, Christovam (org.). Território, ambiente e saúde. Rio de janeiro: FIOCRUZ, 2008.

KALLEBERG, A. O crescimento do trabalho precário: um desafio global. Revista Brasileira de Ciências Sociais, vol. 24, n 69, fev/2009.

KAPPEL, Raimundo F. Portos Brasileiros: novo desafio para a sociedade.

Disponível em:

http://www.sbpcnet.org.br/programas/CONFSIMP/textos/raimundokap pel.htm. Acesso: 30nov2010.

MENDES, Daniele. Sobrevivendo à Marinha Mercante: trabalhadores do mar. In: Revista Anamatra. Ano XVIII. No $52-1^{\circ}$ semestre de 2007 . Vida à bordo: a realidade do trabalhador marítimo brasileiro (ISSN 1981 - 4941).

MÉSZÁROS, I. Desemprego e Precarização: Um grande desafio para a esquerda.

Disponível em www.resistir.info/crise/desemprego_precarizacao.html Acesso em 02 de abril de 2013.

MONKEN, M. (org.). O território na saúde: construindo referências para análises em saúde e ambiente. In: BARCELLOS, Christovam (org.). Território, ambiente e saúde. Rio de janeiro: FIOCRUZ, 2008.

NEVES, Delma Pessanha. Os agricultores de várzea no Médio Solimões: condições socioambientais de vida. In: LIMA, Deborah (Org.). Diversidade socioambiental nas várzeas dos rios Amazonas e Solimões: perspectivas para o desenvolvimento da sustentabilidade. Manaus: IBAMA; PROVÁRZEA, 2005.

ODUM, E. P. Ecologia. Rio de janeiro: GUANABARA, 1988.

OLIVEIRA, Roberto Cardoso de. O trabalho do antropólogo. 2 ed. São Paulo: UNESP, 2000.

OLIVEIRA, José Aldemir de. "Cidades, rios e floresta: raízes fincadas na cultura e na natureza”. In: BRAGA, Sérgio Ivan Gil (Org.). Cultura popular, patrimônio imaterial e cidades. Manaus: EDUA, 2007. 
PAIXÃO, C. \& FLEURY, R. C. Trabalho portuário: a modernização dos portos e as relações de trabalho no Brasil. 2 ed. São Paulo: Método, 2008.

PENHA, Eli Alves. Território e territorialidade: considerações histórico-conceituais. In: IBGE. Instituto Brasileiro de Geografia e Estatística. Revista Brasileira de Geografia.Vol 1, n 1, jan/mar, 1939. Rio de Janeiro, IBGE, 1939. (Publicado em 26/05/1995)

PEREIRA, Cloves Farias; SILVA, Suzy Cristina Pedroza da; WITKOSKI, Antônio Carlos; CRUZ, Manuel de Jesus Masulo da \& FRAXE, Therezinha de Jesus Pinto. Territorialidades específicas e formas de apropriação dos territórios aquáticos no Baixo Solimões. In: FRAXE, Terezinha de Jesus Pinto et al. (Org.). A pesca na Amazônia Central - Ecologia, conhecimento tradicional e formas de manejo. Manaus: EDUA, 2009.

PINHEIRO, Maria Luiza Ugarte. A cidade sobre os ombros: trabalho e conflito no Porto de Manaus (1889-1925). Manaus: EDUA, 2003.

PRATA, P. R. Desenvolvimento econômico, desigualdade e saúde. Caderno Saúde pública, 1994.

PRESTES, Laranna Hatta. Saúde do trabalhador: um estudo sobre as condições de trabalho e saúde dos carregadores e transportadores de bagagens do porto de Parintins/Am. Monografia (Trabalho de conclusão de curso de bacharelado em Serviço Social). Parintins: UFAM, 2011.

RAFFESTIN, C. Por uma geografia do poder. São Paulo: Ática, 1993.

SANTANA, L. H. \& SCHERER, E. Trabalho e ambiente no caos do cais da Manaus moderna. In: SCHERER, E. \& OLIVEIRA, J. A. (Orgs.). Amazônia: território, povos tradicionais e ambiente. Manaus: EDUA, 2009.

SANTOS, M. e SILVEIRA, M. L. O Brasil: território e sociedade no início do século XXI. Rio de janeiro: RECORD, 2001.

SANTOS, M. A naturez̧a do espaço: técnica e tempo; razãa e emoção. 4 ed. São Paulo: EDUSP, 2008.

SAUNIER, Tonzinho. Parintins: memória dos acontecimentos históricos. Manaus: Valer/Edições do Governo do Estado, 2003.

SOUZA, M. J. L. O território sobre espaço e poder, autonomia e desenvolvimento. In: CASTRO, I. E.; COSTA, P. C. G. e CORREAA, R. L. (Orgs.). Geografia: conceitos e temas. Rio de janeiro: BERTRAND BRASIL, 1995. 
TAVARES, Maria Augusta. Os fios (in) visiveis da produção capitalista: informalidade e precarização do trabalho. São Paulo: Cortez, 2004.

TOCANTINS, Leandro. O rio comanda a vida - uma interpretação da Amazônia. 9 ed. Manaus: Valer, 2000.

TRINDADE JUNIOR, Saint-Clair Cordeiro; SILVA, Marcos Alexandre Pimentel da; MALHEIRO, Bruno Cezar Pereira. Belém, a cidade e o rio: uma apresentação do tema. In: TRINDADE JUNIOR, Saint-Clair Cordeiro; SILVA, Marcos Alexandre Pimentel da (Orgs.). Belém: a cidade e o rio na Amazônia. Belém: EDUFPA, 2005. p. 9-11. 